\title{
EMPLOYING WIRELESS NETWORKS IN ENHANCING OCCUPATIONAL SAFETY AT THE DEVELOPING SEAPORT - TWO PROPOSALS
}

\author{
Sanja Bauk, Prof. Dr. \\ University of Montenegro, Faculty of Maritime Studies, Montenegro \\ RWTH Aachen University, Institute for Theoretical Information Technology, Germany \\ Anke Schmeink, Prof. Dr.-Ing. \\ RWTH Aachen University, Institute for Theoretical Information Technology, Germany \\ Joan Colomer \\ Polytechnic University of Catalonia, School of Telecommunications Engineering, Spain
}

\begin{abstract}
The paper proposes two Wireless Body Area Network Sensors (WBANSs) scenarios at the logical and simulation levels for improving occupational safety and health conditions at the developing seaport environment. The Port of Bar (Montenegro) is taken as an exemplar. The logical model is based on the actual position of the Port of Bar at the seaport market, its needs and capacities for the information systems innovation through technology transfer and diffusion. The simulation model analyses the channel between the body central unit (BCU) of the worker's on port wireless body sub-network and the port access point. The quality of the signal transmission at the physical layer has been tested through a source code generated in the Matlab. The code includes the BCU composite signal modulation, transmission, and demodulation, along with a noise and fading effects analysis. The results of the simulation experiments for the different transmission frequencies and distances between transmitter (worker's BCU) and receiver (port's access point) by using binary phase-shift keying (BPSK) and quadratic phase-shift keying (QPSK) modulation schemes are presented. Some directions for further investigations in this field are given, as well.
\end{abstract}

Keywords: occupational safety, developing seaport, Wireless Body Area Network Sensors (WBANSs), channel simulations, physical layer

\section{INTRODUCTION}

With the advancement of Information and Communication Technology (ICT) which enables smart networking business models, cargo and passenger ports services are nowadays considered like high technological processes enriched by informational and electronic transactions components. However, it is not to be forgotten, transportation and traffic are still physical acts and all ports therefore need terminals including all corresponding capacities and features. The sea ports need primarily the adequate infra and supra-structural capacities, adequate organization, sustainability development planning and numerous other structural, financial, and environmental issues which form the foundation for the ICT superstructures $[1,2]$. This holds true for huge developed sea ports like Shanghai, Singapore, Hong-Kong, Busan, Rotterdam, Kaohsiung, Hamburg, Antwerp, Felixstowe, etc. On the other side, this is not the case for ports of developing countries in the South Adriatic region, e.g., Bar, Durres, Kotor, Ploce. Accordingly, in the focus of the paper shall be the last mentioned ones, primarily the Port of Bar.

Previous research in this field indicates that underdeveloped sea ports at the South Adriatic region suffer from the lack of the appropriate ICT solutions $[1,3,4]$. Some of the analyzed sea ports in this basin, e.g., Bar, Durres and Ploce, do not provide all, or some of the following smart operation processes: vessel 
monitoring, automatic containers control, scheduling and stacking containers, monitoring of cargo in stock, etc. These ports have mainly partial, fragmented ICT solutions for supporting some administrative and operational procedures, but they commonly do not have Enterprise Resource Planning (ERP), Customer Relationship Management (CRM) software solutions, Electronic Data Interchange (EDI) service, Vessel Traffic Management Information Systems (VTMIS), National Maritime Single Windows (NMSWs), Electronic Logistics Marketplace (ELM) access, etc. In addition, according to the previous research work [5-7], the passenger sea Port of Kotor is not digitally present at the appropriate scale on the web, in comparison to some developed EU ports of the same kind, what makes negative implications in terms of its position on the customers' perception maps.

The lack of ICT applications in some cargo and passenger ports within the South Adriatic region might be explained by a relatively small turn over of these ports. Consequently, they are lacking the justification for adopting the above mentioned rather costly ICT solutions which would provide greater automation and complete logistic integration of the ports' administrative and operational processes. From another side, insufficient digital presence of the Port of Kotor, e.g., in comparison to some recognized EU passenger ports can be explained by the lack of some value-added and e-transactional services that this port should provide to the customers.

The question here is: Which kind of ICT solutions are urgently needed and at the same time feasible in developing seaports with focus on the South Adriatic and the Port of Bar in the first instance? - Regardless of the turn over of the ports in this region and the economical and political milieu in which they operate, providing the appropriate employees (primarily on port workers) safety and health management, must be placed in the forefront. Therefore, our idea is to propose two wireless network models convenient for improving working conditions and workers' occupational health and safety. The proposed models should be at the same time cost-effective and relatively easy to be implemented and run. The proposed models can be adapted to satisfy the individual needs and capacities, especially if we bare in mind certain organizational and human capacity limitations that are present in the considered Port of Bar, especially when it comes to installing new ICT solutions, along with their continuous maintenance, providing their flexibility and scalability in the future.

\section{PORT OF BAR: IN BRIEF}

The Port of $\mathrm{Bar}^{1}$ has a favorable geographical position. With the railway line Belgrade-Bar and the road network in its hinterland, along with the intermodal transportation and traffic links with Italian ports Bari and Taranto, it could provide good connections within its rather wide gravitational area. Thanks to its advantageous geographical position it

URL:http://www.lukabar.me/eng/Port_of_Bar.htm; last access, September 2016 might be developed into the distribution center for the whole region. More about the Port of Bar can be found on its web site and in the documentation of numerous regional and EU projects in which realization the Port of Bar has been involved.

In the period from 2007 to 2013, the Port has participated in implementation of several EU projects which concerned [8]:

- strengthening intermodal transport;

- short-sea shipping possibilities;

- integrated logistics chains and attracting innovative investments;

- improving environmental impacts at ten South East European (SEE) ports (TEN ECOPORT);

- establishing a sustainable transport system at the Adriatic coast and in the hinterland;

- improving environmental protection (marine/river pollution);

- detecting dangerous materials under the sea water in the ports' area;

- developing sustainable integral sea-land transport/traffic network;

- concerning integration of maritime and river transport in the logistics chain;

pollution prevention in the SEE ports (ECOPORT 8), etc.

Partners from the EU were at most of these projects leading ones, so that the Port of Bar was not mainly in a position to independently decide on the allocation of the available funds. During the projects implementation everything remains on the level of consideration of previous appropriate practices, data collection, analysis, modeling, but when it comes to the implementation of innovative solutions, it seems that the results are quite weak, almost minor. Attracting foreign investments is not realized in the planned volume due to the high administrative barriers, inconsistencies in law enforcement and economic uncertainty within the region. It seems that this geographical area, including Port of Bar as its strategically important sea-land transportation node, remains in the vacuum of inadequate solutions $[8,9]$. It is necessary to make a clear strategy including the competitive and agile administrative and personnel structures that will devotedly work on achieving development in the sphere of freight multimodal, intermodal, co-modal and/or synchromodal [10] transportation modes in the future.

\section{SAFETY AND HEALTH MANAGEMENT IN THE PORT OF BAR}

Within the projects TEN ECOPORT [11] and ECOPORT 8 [12], some recommendations for further actions towards improvement of working conditions and occupational safety in the Port of Bar are provided. The most harmful environmental and workers' health and safety impacts are identified. The working processes in the Port are also analyzed in detail and the points with the highest level of risk to the workers employed directly on port operations are specified. Most of the safety and health issues in the Port of Bar are described in detail in the Port safety management official acts and within the previously mentioned projects' documentation. On the 
basis of a previous detailed analysis in these fields, here will be given an envisaged approach to the problem, in terms of proposing two WBANSs scenarios which are in accordance with the Port of Bar needs and contemporary ICT based safety management recommendations in this domain.

For the purposes of the project TEN ECOPORT realization, several in-dept interviews with the managers in the Port of Bar were performed [13], and the highlights in terms of the most common risks to which the workers directly on port are exposed are identified. These risks are: working outdoors at various (unfavorable) weather conditions (extremely high or low temperatures, rain, wind, etc.), exposure to the dust during the transshipment of bulk cargos (grains, all types of ores and concentrates, alumina, etc.), maneuvering with obsolete transshipment equipment and transportation devices, manipulating with damaged cargo (bags, pallets, packages, containers, etc.), exposure to the risk of fire (especially during the summer months), etc. In addition, workers on port are realizing mostly monotonous and repetitive operations what results in fatigue which increases the risk of accidents.

Above listed risks correspond to those identified and in detail explained, e.g., by the UK Health and Safety Executive (HSE) and Irish Health and Safety Agency (HSA) in seaports, as credible institutions, including the advices for risks preventing and straightforward reacting in the cases when the accidents unfortunately occurred [14-16]. The HSE also gives the extensive list of references in terms of operational and law regulations in these fields, including the relevant statistics. It is worth to mention here that the UK Port Employment and Accident Rates (2009/2010) statistical report stands: "The estimated annual accident rate for all direct on-port employees was $1.1 \%$, or 1,100 per 100,000 employees. ...An employee of a direct on port company is more than fifty times more likely to have an accident (across all severities) in comparison to an employee based in office." These data support the hypothesis that working directly on a port is really dangerous occupation.

Since the Port of Bar has a low turnover, its workers are spared to the considerable extent of some risks to which are exposed the dock workers in the world's leading ports. Therefore the relatively low level of turnover in the Port of Bar, with the aspect of the risks, might be treated as an advantage. Regardless of this fact, in the following parts of the paper two scenarios are proposed for improving safety and health conditions of workers on docks in the Port of Bar.

The first one is based on WBANSs being attached to the workers' personal protective equipment (hard helmets, protective jackets, or safety vests, and ptotective shoes) including a BCU (Body Central Unit), while the second one deals with wearable WBANSs for scanning and transmitting in regular time intervals vital body (electrophysiological) signals: skin temperature, heart activity, respiratory rate, acceleration, oxygen blood saturation, and level of glucose. Although the additional body signals relevant in assessing and improving overall human body (workers') health conditions today might be used trough: artificial cochlea, artificial retina, camera pill, carbon dioxide sensor, visual sensor, bio-impedance spectroscopy, chipped sweatbands, etc. [17-20], for the purpose of this study, the attention will be put to the firstly listed ones.

\section{SCENARIO 1: WBANSS AS PARTS OF PERSONNEL PROTECTIVE EQUIPMENT}

The workers in the Port of Bar are working mainly at open space (docks, open stacking and warehousing areas, gangways, etc.) under various weather conditions with obsolete manipulative equipment and transportation devices, so they are exposed to the variety of non negligible risks. In order to reduce them, the workers should wear personal protective equipment which at least includes: hard helmet, jacket (safety vest) and protective shoes. Over each piece of these garments are to be attached Radio Frequency IDentification (RFID) tags/chips which provide at least an ID for each of the personal protective equipment parts and the data on its functionality. The RFID tags/chips play here the role of the WBANSs. Besides IDs and tags/chips functionality data, the RFID-sensor device attached to the workers' helmets should also provide the information about the temperature and light inside the helmet, while the RFIDsensor devices on the protective shoes should provide the data on workers' plantar pressure. By measuring temperature and light, it is possible to capture the information about working environment conditions, and by measuring plantar pressure distribution it is possible to get the information about the workers' performed actions (Figure 1).

These WBANSs are wirelessly connected through the access point to the advanced back-end info-communication system which sends warning to the worker in cases if a part of personal protective equipment is missing, or if it is not functional. In such case the worker has to come to the central and change that piece of the protective equipment. Also, the worker will be warned in cases when ambient temperature and light are not appropriate.

Similar scenario has been already employed at the Cagliari International Container Terminal, and analyzed in [21-23]. In these references Sole, et al., deal with radio networks for public safety; avoiding possible false alarms generated by the WBANSs; the system of video cameras for feature recognition; the specific absorption rate (SAR) level analysis, etc. We are focus here on simulating network segment on the physical layer between Body Central Unit (BCU), or handheld RFIDsensors' reader, and the access point or sink node of the port local area network by employing several wireless propagation schemes and two modulation (BPSK and QPSK) types. 


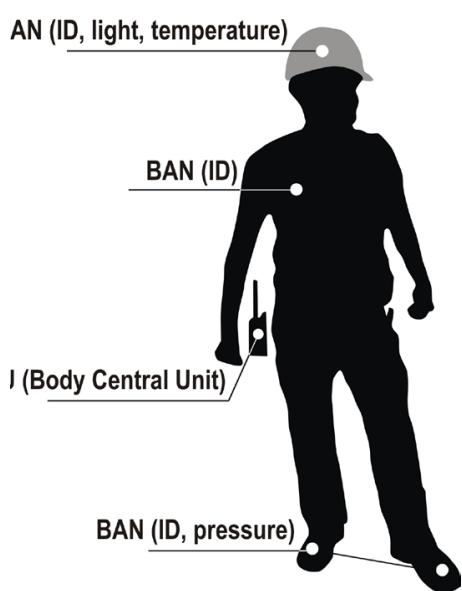

Figure 1. The WBANSs on worker's personal protective equipment RFIDsensors and $B C U$

(Source: Adapted from [21])

The physical layer addresses the lower-level operations of the radio interface for a transmission and reception of packages in a harsh environment like the seaport one. These operations include the frequency selection, transmission power, modulation, signal coding and detection [24].

In the simulation section (Section 6), the communication between RFID tags/sensors and handheld reader is abstracted at this beginning phase of our research work. The content of that information is not clear at the moment and it may vary depending on the port's (i.e., workers, managers and stakeholders) real needs and preferences [25]. The attention is paid to the transmission of the composite signal, generated by previous fusion of personal protective equipment pieces IDs, temperature and light data according to the proposed scenario over the link BCU - the nearest port access point.

\section{SCENARIO 2: WBANSS AS SCANNERS OF WORKERS' VITAL SIGNS}

The second proposed scenario is based on the concept of wearable sensors for measuring in real time workers' electrophysiological data. Since in Montenegro there is no reliable data on professional diseases, the choice of several types of common vital signal sensors which form worker's WBANSs is based mainly on our empirical assessments and intuition. The data published in [26] are incomplete, since they consider only the number of patients who have asked for the help in public health institutions in the recent period. But, there are a lot of people who consciously avoid asking for the health in the public health institutions in Montenegro, even if they have health problems, because the services provided there principally are unfortunately poor. Additionally, most of ill people do not have assets to ask for the help in growing number of specialized private health ambulates. This works for the on port workers, as well. Due to the best of our knowledge, the majority of ill people/workers do not "report" their illness and consequently the official statistics are trustless. Therefore the proposed model at the level of a black box, at the initial stage of our research work, might be of interest to the managers in the Port of Bar and for the health institutions in Montenegro in terms of starting with screening and collecting reliable real-time data on workers' health conditions in a harsh environment.

Figure 2 gives a schematic view of worker's on port WBANSs set, which is composed of several non-intrusive biomedical, vital data sensors for monitoring: (1) heart rate, electrocardiography (ECG), respiratory rate, skin temperature; (2) acceleration; (3) oxygen blood saturation; and (4) glucose level, including optionally insulin pumps, only for those workers who still have some diabetes problems and who are willing to use these sensors-actuators (4).

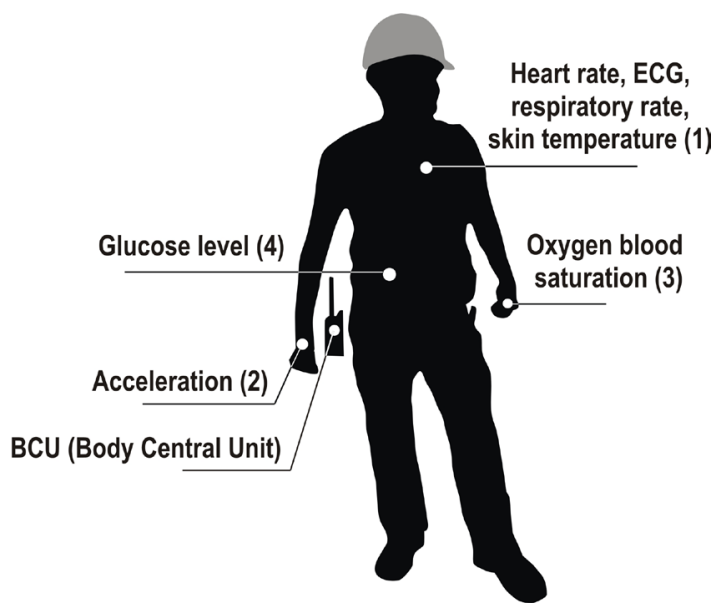

Figure 2. WBANSs for scanning worker's vital signs sensors and $B C U$ (Source: Adapted from [25])

These wearable sensors (Figure 2) are briefly described as follows [25]:

Sensor module (1): It is a compact physiological monitoring module that enables capturing and transmission of comprehensive physiological data on the worker. It is proposed here for measuring: worker's heart rate, electrocardiography (ECG), respiratory rate and skin temperature.

Sensor (2): It is used for measuring the acceleration of a body in an inertial three-dimensional coordinate system, and it plays a key role in human energy expenditure detection and behavioral recognition. Since modern life style demands balanced physical work, the worker's on port physical activity in working-intensive and harsh seaport environment needs permanent recording on daily basis.

Sensor (3): It is commonly used for measuring oxygen blood saturation. It allows monitoring chronic diseases like obstructive pulmonary ones, congestive heart failures or asthma. Since on port workers are exposed to the dust and variety of air pollutants $[11,12]$, we proposed this sensor as an element of the worker's WBANSs set.

Sensor module (4): This sensor module provides the information about the glucose level and it gives the insights into the body's glycemic profile. In addition, it may include the insulin pump therapy that implies the use of multiple daily injections or continuous subcutaneous insulin infusion 
therapy. It should provide an optional health care measure to the workers' on port who still have diabetes problems, strictly under the condition that they are willing to use this type of body sensor-actuator loop.

By all means, there is a plenty of options $[27,28]$ in the considered case in terms which kind of sensors to use, who among the employees will use them or not, depending on their previous health assessment, on their personal will and on managers' decisions. The overlap in sensors' data collecting and processing is to be avoid, as well. It is important to mention that all these sensors should communicate, like in the previously proposed scenario, to the port access point via worker's handheld BCU device. The content of the information which BCU acquire from above proposed and briefly described sensors is still not clear and may vary depending on the port's needs and preferences, along with the workers readiness to become a part of such network. Therefore, it is abstracted here as a payload that is to be transmitted between worker's BCU and the nearest access point at the port perimeter. Similarly to the first proposed scenario the WBANSs are connected through the access points to the appropriate advanced backend info-communication system which sends warnings to the worker in cases if some of his/her biomedical parameters are outside the prescribed boundaries. In such cases the worker has to leave working place and ask for the medical advice and/or help.

\section{COMPARISON OF SCENARIOS 1 AND 2}

It is clear that both presented scenarios are purposeful and it is difficult to determine which one is more effective. We tried to analyze them through three qualitative parameters: medical independence (MI), technological independence (TI) and non-invasiveness (NI). The parameter medical independence means that sensors can realize its purpose without (continuous) medical supervision; technological independence means that sensors can operate independently of other technological systems (i.e., only in coordination with $\mathrm{BCU}$ ), and non-invasiveness means that the sensors are wearable or non-invasive. The values of these parameters are given in Table 1. If (RFID)sensor is independent in medical and technological terms, and/or if it is non-invasive, mark " $x$ " is used; if it is dependent than "o" mark is used, and if it is periodically dependent on the considered parameter(s), mark " $\mathrm{x} / \mathrm{o}$ " is used. Numerical values assigned to the ( $\mathrm{x} ; \mathrm{x} / \mathrm{O}$; o) are respectively $(1.0 ; 0.5 ; 0.0)$. These parameters are heterogeneous, but with positive correlation, what means: it is favorable in all cases that sensors are medically and technologically independent and non-invasive. Therefore, by simple additive method, a rather rough approximation in terms which scenario is more desirable can be made.
Table 1. Qualitative-quantitative comparison (Source: own)

\begin{tabular}{|c|c|c|c|c|}
\hline Scenario & Sensor & MI & TI & NI \\
\hline \multirow{4}{*}{ 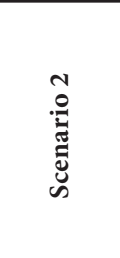 } & $\begin{array}{l}\text { Heart rate, ECG, respiratory rate, skin } \\
\text { temperature }\end{array}$ & $\mathrm{x} / \mathrm{o}$ & $\mathrm{x}$ & $\mathrm{x}$ \\
\hline & Acceleration & $\mathrm{x} / \mathrm{o}$ & $\mathrm{x}$ & $\mathrm{x}$ \\
\hline & Oxygen blood saturation & $\mathrm{x} / \mathrm{o}$ & $\mathrm{x}$ & $\mathrm{x}$ \\
\hline & Glucose level (insulin pump - optionally) & o & $\mathrm{x}$ & o \\
\hline \multicolumn{2}{|r|}{ Score: } & 1.5 & 4.0 & 3.0 \\
\hline \multirow{4}{*}{ 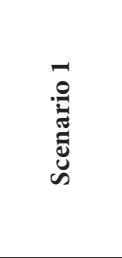 } & RFID $_{\text {Helmet }}$ (ID, light; temperature) & $\mathrm{x} / \mathrm{o}$ & o & $\mathrm{x}$ \\
\hline & $\mathrm{RFID}_{\text {Jacket }}(\mathrm{ID})$ & $\mathrm{x}$ & o & $\mathrm{x}$ \\
\hline & RFID $_{\text {Shoe } 1}(\mathrm{ID}$, pressure $)$ & $\mathrm{x} / \mathrm{o}$ & o & $\mathrm{x}$ \\
\hline & RFID $_{\text {Shoe } 2}(I D$, pressure $)$ & $\mathrm{x} / \mathrm{o}$ & o & $\mathrm{x}$ \\
\hline & Score: & 2.5 & 0.0 & 4.0 \\
\hline
\end{tabular}

For instance the sensor for measuring worker's heart rate, ECG, respiratory rate and skin temperature functions independently, but after a certain time it needs to be read by the physician. Similar situation is with accelerometer and oxygen blood saturation meter; while glycol meter and insulin pump requires more frequent physician scrutiny. The RFID chips with light, temperature and pressure sensors require also periodically medical survey. When it comes to the technologically independent, then the sensors which belong to the scenario 2 can function independently. On the contrary, greater precision can be achieved if the sensors within the scenario 1 work in combination with system of video cameras and RFID readers fixed at strategically points in the port $[22,24,25]$, besides those imbedded in workers' handheld sets (BCUs). Further, three of four sensors associate to the scenario 2 are non-invasive, except glucose pump, which can be use optionally; while all RFID-sensors in scenario 1 are non-invasive. These observations, expressed numerically, are shown in Figure 3.

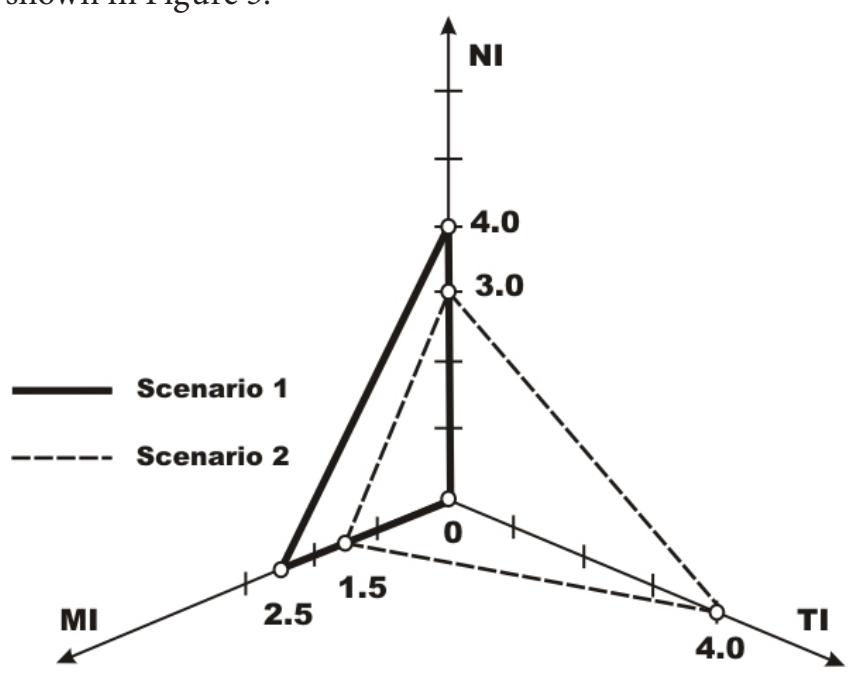

Figure 3. Results of quantitative comparison (Source: own) 
The second scenario is obviously in a considerable advantage to the first one in accordance to the second parameter - technologically independence (TI). Meanwhile, if the port management decides to use the first proposed scenario without supplementing system of video cameras and fixed readers installed on port, it will be preferable, etc. At any rate, this comparative analysis is quite rough, and it can be used only for orientation, it terms how to perform later more detailed one. For this purpose it would be necessary to specify which of the commercial sensors will be used, in which intervals medical supervision will be carried out for each scenario, shall be used additional supporting systems in the case of scenario 1 or not, etc. However, these decisions are up to the port's managers and stakeholders, workers and ICT and medical experts who will be eventually engaged in designing and implementing such scenario(s).

\section{SIMULATION MODEL AND SOME ANALYSIS}

Since here are proposed two different conceptual models for monitoring occupational safety, in Figure 4 is given a wider network scheme that can envelop them. The worker's on port BCU performs RFID-sensors and biomedical sensors data access control and fusion, and transmits them through the access point to the outside world. This means data transmission via broadband modem (fixed, wireless, or mobile one), which provide high-speed connection via Internet, which is here symbolically presented as a cloud, to the advanced backend RFID-sensors' and biomedical sensors' central servers. The high-speed broadband connection can be established as: (i) Wireless Local Area Network (WLAN) by means of Bluetooth, Wi-Fi, ZigBee, UWB, or White-Fi; (ii) Wireless Metropolitan Area Network (WMAN) by means of WiMax USB modems and the towers; and/or (iii) Wireless Wide Area Network (WWAN) by means of cellular or satellite communication systems [29,30], etc. (Figure 4).

If some among the screened on port workers need 24 hours long surveillance (Scenario 2), then they have to wear sensor(s) not only at work, but also at home. In such case, the corresponding connection to the network must exist from the home environment, i.e., the access points at worker's home place should be provided, as well.
Whereas the proposed network structural model is a complex one, in this initial phase of our research work the simulations are limited to a small segment of the network, i.e., on the wireless link between the worker's BCU and the port's access point. Although this looks as a notably simplified simulation procedure, it is significant. Namely, this segment of the network requires at the same time low energy consumption, large scale of nodes mobility in a harsh working environment and high reliability in real-time. Hence, it is surely among the most vulnerable and challenging segments of the network in terms of further research endeavors.

The simulation model is realized in the Matlab (ver. 7.12.1), by an Inter(R) Core $^{\text {tx }}$ i5 processor on $2.4 \mathrm{GHz}$ (4GB RAM). The key steps in creating simulation model of the channel between the worker's BCU and the port's access point are given in Table 2 .

Table 2. Simulation steps in modeling the channel between BCU and access point at the physical layer (Source: own)

\begin{tabular}{|c|c|}
\hline Step 1: & $\begin{array}{l}\text { Definition of the simulation parameters: carrier frequency, } \\
\text { distance between transmitter and receiver, a sequence of input } \\
\text { bits, number of iterations, and Signal-to-Noise-Ration (SNR) } \\
\text { range }\end{array}$ \\
\hline Step 2: & $\begin{array}{l}\text { Calculating Free Space Path Loss (FSPL) by (Eq.1): } \\
\qquad \text { FSPL }=\left(\frac{4 \pi \mathrm{df}}{\mathrm{c}}\right)^{2} \text { (Eq.1), where } \\
\begin{array}{l}\mathrm{d}-\text { is the distance between the transmitter and the receiver }[\mathrm{m}] \\
\mathrm{f}-\text { is the frequency of the carrier }[\mathrm{Hz}] ; \text { and } \\
\mathrm{c}-\text { is the speed of light in vacuum, i.e. [m/s] }\end{array}\end{array}$ \\
\hline Step 3: & $\begin{array}{l}\text { Applying binary phase-shift keying (BPSK) and quadratic } \\
\text { phase-shift keying (QPSK) modulation schemes on real and } \\
\text { complex signal components respectively }\end{array}$ \\
\hline & $\begin{array}{l}\text { Generating Gaussian noise and computing the standard } \\
\text { deviation for each SNR value by (Eq.2): }\end{array}$ \\
\hline Step 4: & $\begin{array}{l}\qquad \mathrm{P}_{\text {noise }}=\sqrt{\frac{\mathrm{P}_{\text {signal }}}{\mathrm{SNR} \cdot \mathrm{FSPL}}} \text { (Eq.2), where } \\
\mathrm{P}_{\text {noise }}-\text { is the power of noise }[\mathrm{W}] ; \\
\mathrm{P}_{\text {signal }}-\text { is the power of transmitting signal }[\mathrm{W}] \text {; and } \\
\text { SNR - is the signal-noise-ratio }\end{array}$ \\
\hline Step 5: & Simulating Additive White Gaussian Noise (AWGN) \\
\hline Step 6: & $\begin{array}{l}\text { Generating recovering (source) signal by Wiener filter which } \\
\text { minimizes the mean square error between the estimated } \\
\text { random process and the desired one }\end{array}$ \\
\hline Step 7: & $\begin{array}{l}\text { Compute the number of Bit Error Rate (BER) after the slicer, } \\
\text { i.e., part of the code that compares the original signal with the } \\
\text { recovered one, point by point, specifying if it is well recovered } \\
\text { or not }\end{array}$ \\
\hline Step 8: & Plotting graphics: BER vs. SNR \\
\hline
\end{tabular}

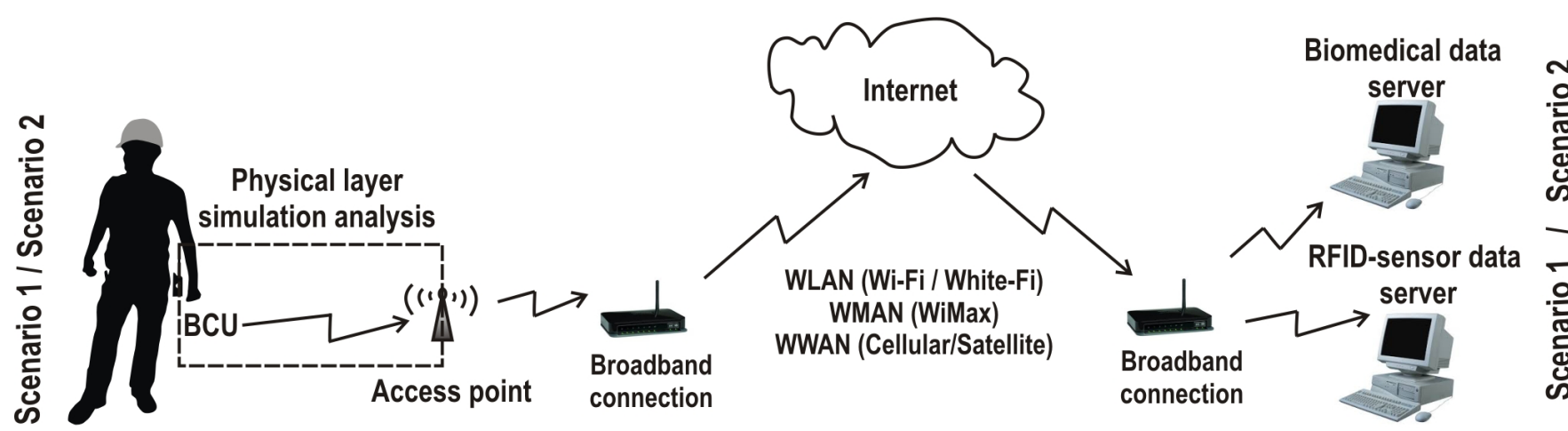

Figure 4. A conceptual scheme of the worker's WBANSs connection to the backend servers (Source: own) 


\section{SIMULATION ANALYSIS}

On the basis of the Matlab code briefly described above and summarized in Table 2, the relations between the transmitted signal, between worker's BCU and port's access point, BER and SNR are presented. In the first case the considered relation is examined for characteristic carrier frequencies in different wireless technologies [24], e.g., 915 [MHz], 2.4 [GHz] and 3.1 $[\mathrm{GHz}]$. The simulation results are presented in Figure 5, and it is obvious that in all cases the BER decreases as SNR increases. The simulations are run through several thousand loops. It is clear that higher frequency causes higher BER and inversely.

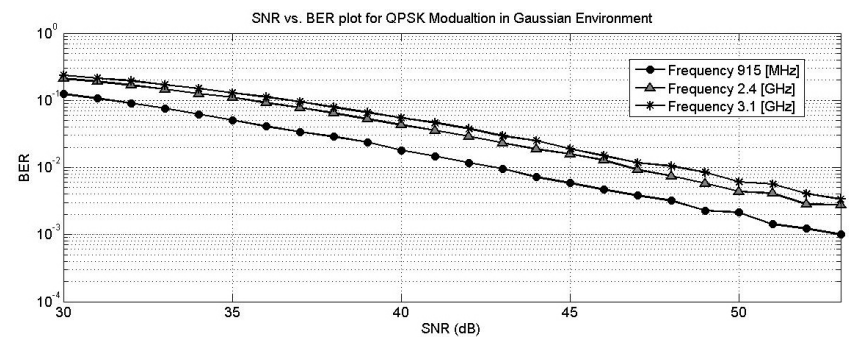

Figure 5. SNR vs. BER for three characteristic wireless networks frequencies (Source: own)

Similar simulations are realized for different distances between the transmitter (worker's BCU) and the receiver (port's access point). The characteristic distances between end nodes of the simulated network segment of 10,20 , and $30[\mathrm{~m}]$ are considered (Figure 6). It is clear that the BER decreases by rising SNR in all considered cases, in a manner that greater distance corresponds to a higher BER and conversely. The simulations are run like in the previous case trough several thousand loops.

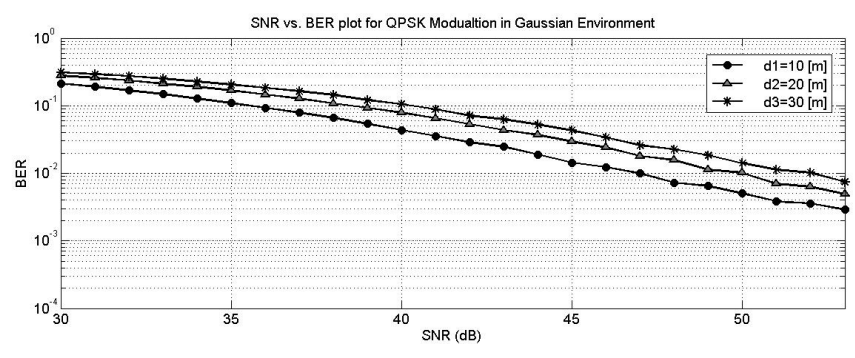

Figure 6. SNR vs. BER for various distances between end-nodes (BCU and access point) (Source: own)

In addition to the simulations for typical wireless frequencies and covered distances, some simulations for White-Fi are performed. It is to be pointed out that by using White-Fi signal absorption can be avoid easily, while some additional, otherwise unused TV frequencies, might be used. In order to achieve this, the new technologies and rules are developing, like cognitive radio, geographic sensing, etc. [31]. Hereto, due to the best of our knowledge, there are no obstacles for implementing White-Fi in the considered port environment.

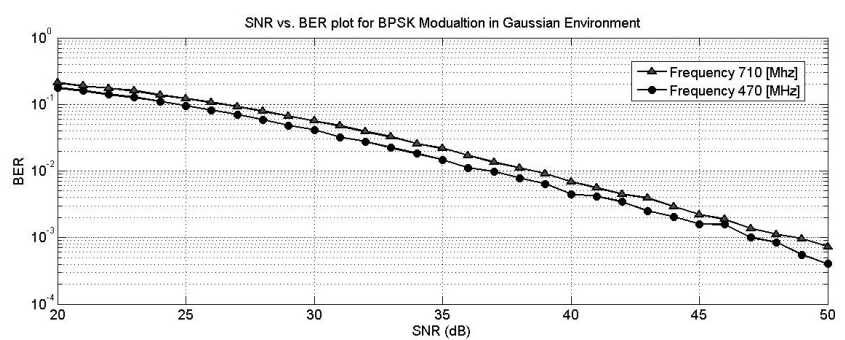

Figure 7. SNR vs. BER for two characteristic White-Fi frequencies (Source: own)

In Figure 7 are shown the transmission simulation results for two typical White-Fi frequencies: $470[\mathrm{MHz}]$ and 710 $[\mathrm{MHz}]$. The simulations are realized by using the BPSK modulation scheme, and it is obvious that the BER decreases to E-03 as SNR reaches about 50 [dB]. The obtained simulation results in all considered cases (see Figure 5, 6 and 7) speak in favor of the applied modulation scheme, path loss and noise models, so they can be employed as a sound basis for further, more extensive, analysis in this domain. The trade-off between BPSK and QPSK modulation schemes is simulated, as well, and it is observed that the BER is slightly lower in the case of BPSK, but it is negligible in terms of the transmitted data amount which is doubled by using QPSK [24, 32-35].

With the aim to add a dynamic dimension to the simulation analysis, we have analyzed the scenario with, e.g., four workers and four access points at $2.4[\mathrm{GHz}]$ over the port area of 1000 $\left[\mathrm{m}^{2}\right]$. The change interval is 1 [sec] with 0.1 [sec] of standard deviation. This means that over 1 [sec] each node will make a move at a specified speed. The speed was set to emulate the movement of a worker, approximately $3[\mathrm{~m} / \mathrm{sec}]$. The transmission power was set to $[-30 \mathrm{~dB}]$. Figure 8 shows the relation of the reception power of the fixed access points and the delay. The distance and delay are linked by the speed of transmission of the signal. It is easy to notice that the received power is less as the distance and the delay decreases.

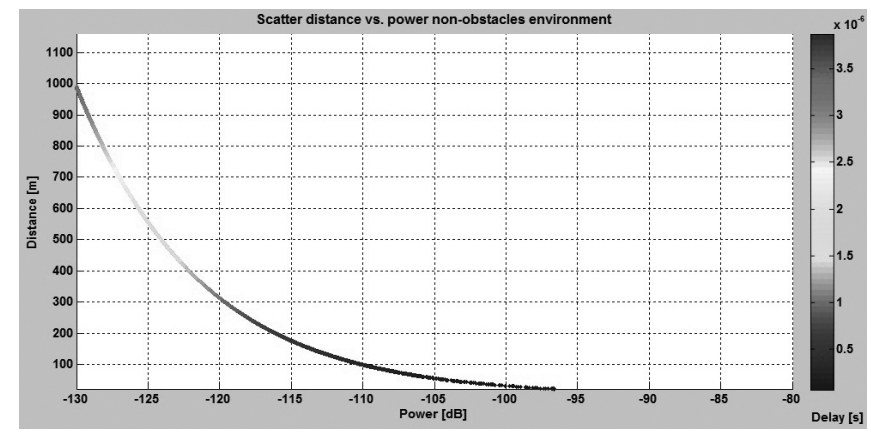

Figure 8. The distance/delay vs. received power for a non-obstacle scenario over the port layout (Source: own)

If we introduce the obstacles, the scatter function will be changed (Figure 9). As the simulation experiment has been done over the layout of the Port of Bar container and general cargo terminal, the obstacles were imaginary containers blocks. Therefore, the obstacles' approximate measures were 200x100x4 [m]. The containers (obstacles) have a specific relative permittivity and permeability, which also affects the 
channel. When the distance and the delay were biger, the received power became lower and vice versa.

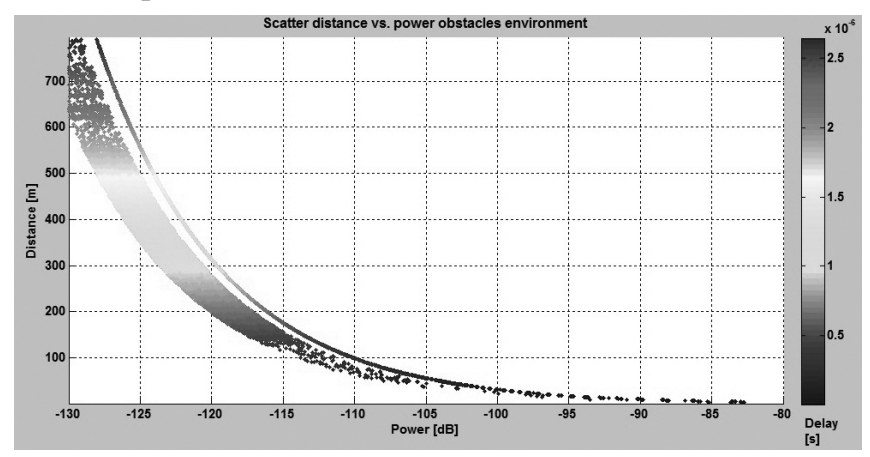

Figure 9. The distance/delay vs. received power for a scenario with obstacle over the port layout (Source: own)

The scatter diagram in the scenario with obstacles has two significant shapes. The thin one represents the line of the sight signal, while the thicker one represents the reflections or the signals that pass through the obstacle. The difference between the received power of the line of a sight signal and the received power of a reflected one, or those that passes through the obstacle, is approximately 1-5 [dB]. Consequently, the scenario with obstacles needs a higher value of SNR in order to achieve the same level of BER like in the case of non-obstacle environment.

\section{CONCLUSIONS}

In the paper are proposed conceptually two WBANSs scenarios for monitoring workers' occupational safety and health conditions at the developing seaport environment. The Port of Bar (Montenegro) is taken as an example. A short overview of its current position at the seaport market in is given. Also, some projects recently realized in the Port in the environmental and occupational safety domains are briefly presented and used as a base for the proposed occupational safety models.

The first proposed scenario has direct impact on improving workers' safety through strengthening their awareness about the necessity of the protective equipment proper use. By employing this scenario, managers can locate workers, get insight in their behavior and undertake the appropriate safety measures. On the other side, scanning and collecting data on workers' health conditions, within the context of the second scenario, might be useful in protecting workers' health and for collecting the data that can be used later for establishing cross-correlations between workers' health and their eventual (occupational) diseases.

One of the most vulnerable and at the same time challenging segments of the proposed scenarios, i.e., those between moving worker's BCU and fixed port's access point, is analyzed through the simulation experiments, and the following is drawn out:

- By analysing different characteristic frequencies for wireless communications and distances between the transmitter (BCU) and receiver (access point), a satisfying level of BER is achieved by using both binary phase-shift keying (BPSK) and quadratic phase-shift keying (QPSK) modulation schemes;

- In addition to standard frequencies for wireless communications (915 [MHz], $2.4[\mathrm{GHz}]$, and $3.1[\mathrm{GHz}]$ ) between the transceivers, two characteristic frequencies from White-Fi spectra $(470[\mathrm{MHz}]$, and $710[\mathrm{MHz}])$ have been examined, while the satisfying level of BER has been achieved, too;

- The scatter functions, in the simulation environment without and with obstacles, both contain the line of sight signals, and their values are the same in both cases;

- In the scenario which includes the obstacles, the attenuation of the signal of 1-5 [dB] has been noticed (shadowed area below line of sight signal in Figure 9), etc.

The managers in the Port of Bar can use the proposed WBANSs scenarios, along with the simulations results, as the landmarks in the course of adopting these or similar models and in the negotiation processes with the ICT experts responsible for the (eventual) implementation in the future. It should be noted that both concepts simultaneous adaptation can make a burden for workers and port management.

Our work is not without shortages and below are noted some of them. Albeit the considered topic is a hotspot of contemporary research in several scientific disciplines, numerous and complex problems still remain. There are a lot of challenges when it comes to the on- and in-body sensors' technology, data fusion and network communication technology. The networks of such kind also need evolving standards for co-existence and data transfer with other networks and Internet. In this paper, simulations are realized rather at the level of black box over one small and simplified segment of the network. Therefore, the further experiments should be oriented toward considering larger network segment, or the entire network, in terms of data processing algorithms, communication protocols, power consumption, network flexibility and robustness. Bearing these in mind, our further investigations will be focused on the simulations of the network with larger number of moving BCUs and fixed port's fixed access points. These simulations will be done by means of Matlab, LabView, Opnet and/or Omnet++ tools.

In addition to the above mentioned limitations in the technological realm, there are several organizational and ethical issues which deserve to be examined. The level of the Port's mangers and stakeholders readiness for providing funds and employing such safety and health solutions should be evaluated. The possibilities of engaging medical institutions and experts, besides ICT ones, are to be examined, as well. And finally, the willingness of the on port workers to become constituents of the proposed network(s) is to be assessed. The achieved results of these planned examinations might cause considerable modifications of the proposed WBANSs models. 


\section{REFERENCES:}

1. Bauk S., Sekularac-Ivosevic S., Jolic N., Seaport positioning supported by the combination of some quantitative and qualitative approaches, Transport, Vol. 30, No. 4, October 2015, pp. 385-396.

2. Turban E., Volonino L., Information Technology for Management - Transforming Organizations in the Digital Economy, $7^{\text {th }}$ Edition, Asia: John Wiley \& Sons, 2010.

3. Šekularac-Ivošević S., Bauk S., Gligorijević M., Combining the concepts of benchmarking and matrix game in marketing (re)positioning of seaports, PROMET-Traffic \& Transportation, Vol. 25, No. 5, October 2013, pp. 431-443.

4. Šekularac-Ivošević S., Bauk S., Quantitative and Qualitative Basis of Customer Relationship Management Concept Development in the Adriatic Ports, Transactions on Maritime Science, Vol. 1, No. 1, April 2011, pp. 109-116.

5. Vitić-Ćetković A., Bauk S., E-services and Positioning Passenger Ports in the Context of Cruise Tourism Promotion, PROMET-Traffic \& Transportation, vol. 26, no. 1, January 2014, pp. 83-93.

6. Bauk S., Passenger Ports Benchmarking due to the E-services They Offer, Montenegrin Journal of Economics, vol. 6, no. 11, July 2010, pp. 49-56.

7. Bauk S., et al., A Passenger Port Benchmarking due to the E-services it Offers, Proc. of the $13^{\text {th }}$ International Conference on Transport Science - ICTS, $27^{\text {th }}-28^{\text {th }}$ May, Portorož, Slovenija, 2010, pp. 1-8.

8. Bauk S., Recommendations for new structural funds directed to new transport infrastructures and services for the period 2014-2020, WP 3.1 of the IPA Project of Europe-Adriatic Sea-Way Freight - EASYCONNECTING, code: $1^{\circ}$ str.0002, May, 2015, pp. 1-110.

9. Biščević $\mathrm{H}$., The Western Balkan's new choice - joint development or individual depression, World Commerce Review, 2012, pp. 1-3.

10. Harris I., Wang Y., Wang H., ICT in multimodal transport and technological trends: Unleashing potential for the future, Int. J. Production Economics, 159 (2015), pp. 88-103.

11. Project documentation: TEN ECOPORT, Transnational ENhacement of ECOPORT 8 Network, code: SEE/D/01889/2.2/x, Port of Bar (Montenegro) Improving Environmental Management System at Container Terminal, May, 2014.
12. Project documentation: ECOPORT 8, Environmental management of trans-border corridor ports, code: SEE/ A/218/2.2/x, Port of Bar (Montenegro) Final Report, July, 2013.

13. Bauk S., Feasibility study for the Port of Bar, TEN ECOPORT, Transnational ENhacement of ECOPORT 8 Network, code: SEE/D/01889/2.2/x, Jun, 2014, pp. 1-38.

14. Health and Safety Executive (HSE), A quick guide to health and safety in ports (URL: http://www.hse.gov.uk/ ports/topics.htm; last access, September 2016), London, UK, January, 2011, pp. 1-11. (last access, September 2016)

15. Health and Safety Executive (HSE), Safety in docks. Approved Code of Practice (URL: http://www.hse.gov.uk/ ports/topics.htm; last access, September 2016), London, UK (ISBN: 9780717665723), 2014.

16. Health and Safety Agency (HSA), Management of Health and Safety in Ports and Docks - Information Sheet, Ireland (URL: http://www.hsa.ie/eng/; last access, September 2016), February, 2015, pp. 1-3.

17. Lai X., Liu Q., Wei X., et al., A Survey of Body Sensor Networks, Sensors, 2013, 13, doi: 10.3390/s130505406, pp. 5406-5447.

18. Beckmann L., Cordes A., Saygili E., Schmeink A., Schauerte P., Walter M., Leonhardt S., Monitoring of body fluid in patients with chronic heart failure using Bioimpedance-Spectroscopy, Dössel O., Schlegel W.C. (Eds.): WC IFMBE Proceedings 25/VII, 2009, pp. 532-535.

19. Kahn J.Y., Yuce M.R., Wireless Body Area Network (WBAN) for Medical Applications, in New Developments in Biomedical Engineering (Compolo D., Ed.), Chapter 31, In Tech, January, 2010, pp. 591-627.

20. Sole M., Musu C., Boi F., Giusto D., Popescu V., RFID sensor network for workplace safety management, Proc. of $18^{\text {th }}$ IEEE Conference Emerging Technologies \& Factory Automation - ETFA, $10^{\text {th }}-13^{\text {th }}$ September 2013, Cagliari, Italy, pp. 1-4.

21. Sole M., Musu C., Boi F., Giusto D., Popescu V., Control system for workplace safety in cargo terminal, Proc. of the $9^{\text {th }}$ IEEE International Wireless Communications and Mobile Computing Conference, $1^{\text {st }}-5^{\text {th }}$ July 2013, Sardinia, pp. 1035-1039.

22. Sole M., Communication technologies and data processing for safety, Doctoral Dissertation, University of Cagliari, Italy, March, 2014. 
23. Mahalik N.P. (Ed.), Sensor Networks and Configuration - Fundamentals, Standards, Platforms, and Applications, Springer, Vrlag Berlin Heilderberg, 2007.

24. Brandao P., Abstracting information on body area networks, Technical Report No. 812 on Doctoral disertation, University of Cambridge Computer Laboratory, January, 2012.

25. Montenegro Statistical Office, Statistical Year Book, Chapter 28 - Health (pp. 176-182), Monstat, Podgorica, 2014.

26. Ragesh G. K., Baskaran K., A Survey on Futuristic Health Care System: WBANs, International Conference on Communication Technology and System Design 2011, Procedia Engineering 30, 2012, pp. 889 - 896.

27. Crosby G.V., Ghosh T., et al., Wireless Body Area Networks for Healthcare: A Survey, International Journal of Ad hoc, Sensors \& Ubiquitous Computing (IJASUC), Vol. 3, No. 3, June 2012, pp. 1-25.

28. Balzan P., Business Driven Information Systems, $3^{\text {rd }}$ Edition, McGraw-Hill, New York, NY, 2012.

29. Haag S., Cummings M., Management Information Systems for the Information Age, McGraw-Hill, New York, NY, 2013.

30. IEEE 802.11af White-Fi Technology - an overview of the IEEE 802.11af or White-Fi proposal for Wi-Fi using the TV White spaces and cognitive radio technology (URL: http://www.radio-electronics.com/info/wireless/wi-fi/ ieee-802-11af-white-fi-tv-space.php; last access, September 2016)

31. Javaid N., Khan N. A., Shakir M., et al., Ubiquitous Health Care in Wireless Body Area Networks - A Survey (URL: http://arxiv.org/ftp/arxiv/papers/1303/1303.2062.pdf; last access, September 2016)

32. Khan J.Y., Yuce M. R., and Karami F., Performance evaluation of a wireless body area sensor network for remote patient monitoring (URL: http://www.eng.newcastle. edu.au/ mry122/EMBC08 OPNET Zigbee Final.pdf; last access, September 2016)

33. Bangash J.I., Abdullah A.H., et al., A survey of Routing Protocols in Wireless Body Sensor Networks, Sensors, 2014, 14, doi: 10.3390/s140101322, pp. 1322-1357.

34. Breed G., Bit Error Rate: Fundamental Concepts and Measurement Issues, High Frequency Electronics, Summit TecnoMedia, January 2013, pp. 46-48 (URL: http://www. highfreqelec.summittechmedia.com/Jan03/HFE0103 Tutorial.pdf; last access, September 2016)

\section{CONTACT WITH THE AUTHOR}

\author{
Sanja Bauk \\ e-mail:bsanjaster@gmail.com \\ University of Montenegro \\ Faculty of Maritime Studies \\ Dobrota 36, 85330 Kotor
}

MONTENEGRO

RWTH Aachen University

Institute for Theoretical Information Technology ICT cubes

Kopernikusstr.16, D-52074 Aachen

GermanY

Anke Schmeink

e-mail:anke.schmeink@rwth-aachen.de RWTH Aachen University

Institute for Theoretical Information Technology ICT cubes

Kopernikusstr.16, D-52074 Aachen

GERMANY

Joan Colomer

e-mail: joan.colomer.rodriguez@gmail.com

Polytechnic University of Catalonia

School of Telecommunications Engineering

Jordi Girona Str. 1-3, 08034 Barcelona

SPAIN 